\title{
(What's so funny 'bout) peace, love, and thyroid hormone
}

\author{
Jonathan M. Chen, MD
}

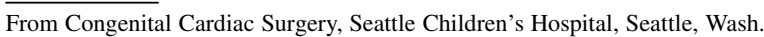

Disclosures: Author has nothing to disclose with regard to commercial support.

Received for publication May 31, 2018; revisions received May 31, 2018; accepted for publication June 1, 2018; available ahead of print July 11, 2018.

Address for reprints: Jonathan M. Chen, MD, Congenital Cardiac Surgery, Seattle Children's Hospital, 4800 Sand Point Way NE - RC2.820, Seattle, WA 98105 (E-mail: jmchen@uw.edu).

J Thorac Cardiovasc Surg 2018;156:1218-9

0022-5223/\$36.00

Copyright (c) 2018 by The American Association for Thoracic Surgery

https://doi.org/10.1016/j.jtcvs.2018.06.014

Since Bettendorf and colleagues' landmark study, ${ }^{1}$ and with several iterations of the Triiodothyronine (T3) Supplementation in the Infants and Children Undergoing Cardiopulmonary Bypass (TRICC) trial, it has become evident that $\mathrm{T} 3$ administration to pediatric patients may help to mitigate the deleterious effects of their functionally "hypothyroid" state after cardiopulmonary bypass. ${ }^{2-4}$ Although the direct mechanism of this relative hypothyroidism is not well understood, some have suggested a relationship between the cytokine inflammatory response and the overall T3 suppression, and (perhaps relatedly) that the salutary effects of T3 may have varying effect based on age and case complexity. ${ }^{2-4}$ In this issue of the Journal, Talwar and colleagues ${ }^{5}$ present outcomes for infants undergoing open surgery as part of a randomized trial using oral thyroxine (T4).

Similar to the TRICC trial results, those of Talwar and colleagues $^{5}$ demonstrate improvement in the $\mathrm{T} 4$ cohort overall with regard to low cardiac output syndrome and inotropic score. ${ }^{5} \mathrm{~T} 4$ was administered orally 12 hours before surgery, on the day of operation, and daily for each intensive care unit day. Those in the "complex" subgroup (eg, transposition, truncus) demonstrated statistically significant reduction in intensive care unit and hospital stays and a time-limited effect with regard to inotropic score; patients in the "simple" group (ventricular septal defects) did not show comparable benefit.

On balance, the concepts are similar to those found in the TRICC study, namely, that the beneficial effects of $\mathrm{T} 3$ or $\mathrm{T} 4$ (as a precursor to T3) may be most pronounced in those younger than 5 months (TRICC study) or those more "complex" cases (Talwar and colleagues' study $^{5}$ ). Although speculative, it may be that the older patient with lower case complexity may have less of an inflammatory insurrection - or at least less relative "hypothyroidism"- as to demonstrate a reduced benefit from its correction. To note, both Talwar and colleagues' study ${ }^{5}$ (New Delhi) and the most recent

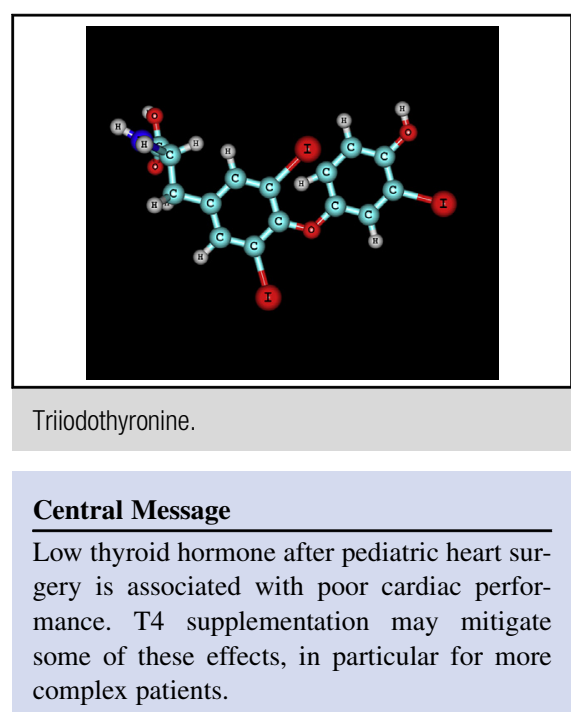

See Article page 1209.

publication from the TRICC investigators (Indonesia) represent cohorts whose disease profiles may not reflect those worldwide, thereby begging for a dedicated trial in high-risk newborns. ${ }^{4-6}$

In infants, low thyroid hormone plasma concentrations after cardiac surgery appear to cause a phenotype of poor cardiac performance akin to clinical hypothyroidism. Instinctively, prophylactic replacement seems logical, in particular for those younger patients undergoing more complex procedures, and to be certain its administration is even now not uncommonly part of the pharmacologic "kitchen sink" thrown at recalcitrant poor hemodynamics. Although not elucidated in Talwar and colleagues' study, ${ }^{5}$ adverse events related to T3/T4 administration in this clinical setting have historically been low, so one might argue why not administer T3/T4 to every child undergoing open surgery $?^{2}$ Naturally, what is good for the goose may not actually be good for the gander, and the variability in response to T3/T4 warrants refinement in our understanding of its best application. Like peace and love, thyroid hormone may have considerable effect-in particular in the domain of diastology — enough so that its import should not be underestimated. Identifying not only the best timing and method of delivery but also the ideal target population will be critical for its optimal application.

\section{References}

1. Bettendorf M, Schmidt KG, Grulich-Henn J, Ulmer HE, Heinrich UE. Tri-iodothyronine treatment in children after cardiac surgery: a double-blind, randomized, placebo-controlled study. Lancet. 2000;356:529-34. 
2. Portman MA, Slee A, Olson AK, Cohen G, Karl T, Tong E, et al. Triiodothyronine supplementation in infants and children undergoing cardiopulmonary bypass (TRICC). A multicenter placebo-controlled randomized trial: age analysis. Circulation. 2010;122(suppl 1):S224-33.

3. Priest JR, Slee A, Olson AK, Ledee D, Morrish F, Portman MA. Triiodothyronine supplementation and cytokines during cardiopulmonary bypass in infants and children. J Thorac Cardiovasc Surg. 2012;144: 938-43
4. Marwali EM, Boom CE, Budiwardhana N, Fakhri D, Roebiono PS, Santoso A et al. Oral triiodothyronine for infants and children undergoing cardiopulmonary bypass. Ann Thorac Surg. 2017;104:688-97.

5. Talwar S, Bhoje A, Khadagawat R, Chaturvedi P, Sreenivas V, Makhija N, et al Oral thyroxin supplementation in infants undergoing cardiac surgery: a doubleblind placebo-controlled randomized clinical trial. J Thorac Cardiovasc Surg. 2018;156:1209-17.

6. Eghtesady P. Invited commentary. Ann Thorac Surg. 2017;104:696. 